\title{
Scale-dependent effects of habitat fragmentation on reproduction in the annual Circaeaster agristis, a narrow endemic and threatened species
}

\author{
Jie-Cai Zhao', Jun Luo ${ }^{1}$, Chun-Ping Yang ${ }^{1}$ and Guo-Xing Cao ${ }^{1,2^{*}}$
}

\begin{abstract}
Background: Habitat fragmentation and the resulting decline in population size and density commonly reduce the reproduction of rare and threatened species. We investigated the impacts of population size and density on reproduction in more than 30 populations of Circaeaster agristis, a narrow endemic and threatened species, in 2010 and 2011. We also examined the effects of NND (nearest neighbor distance) and LNS (local neighbor size), within radii of $0.1 \mathrm{~m}, 0.2 \mathrm{~m}$ and $0.3 \mathrm{~m}$, on reproduction in two of the populations in 2011.

Results: Population size did not affect fruit (seed) number and fruit set in either year studied. Population density had an indirect negative effect on fruit number and fruit set as a consequence of a negative effect on plant size in 2010, but had no effect on fruit number and fruit set in 2011. Within populations, individual fruit number did not change, and individual fruit set increased independent of plant size, in response to increasing NND. Both individual fruit number and individual fruit set increased, independent of plant size, with increases in LNS within a $0.1 \mathrm{~m}$ radius, but did not change with increases in LNS within radii of between $0.1 \mathrm{~m}$ and $0.2 \mathrm{~m}$ radii or between $0.2 \mathrm{~m}$ and $0.3 \mathrm{~m}$.

Conclusions: The effect of habitat fragmentation on reproduction of $C$. agristis is scale-dependent. In contrast to the generally accepted idea that fragmentation reduces plant reproduction, reproductive success may increase in sparse populations or increase in response to decreases in LNS in C. agristis.
\end{abstract}

Keywords: Circaeaster agristis; Habitat fragmentation; Population size; Population density; Reproduction; Scale-dependency

\section{Background}

Habitat fragmentation is a worldwide phenomenon, and is considered to be one of the major threats to the persistence and viability of plant populations (Eriksson and Ehrlén 2001; Oostermeijer, 2003). Habitat fragmentation often causes a decline in the size and density of populations, thereby altering abiotic and biotic environmental conditions (Wilcove et al., 1986; Saunders et al., 1991), all of which can affect the reproductive success of plants.

Experimental studies and field observations have shown that plants in small and sparse populations,

\footnotetext{
* Correspondence: cgxing@sicau.edu.cn

${ }^{1}$ Department of Forestry, Sichuan Agricultural University, Yaan 625014, China ${ }^{2}$ Xishuangbanna Tropical Botanical Garden, Chinese Academy of Sciences, Mengla 666303, China
}

because of their smaller display size and lower supply of rewards, often receive lower visitation rates (Ågren, 1996; Kunin, 1997; Weber and Kolb 2013), and experience smaller pollen loads (Bosch and Waser, 1999; Waites and Ågren, 2004; Jakobsson et al., 2009), resulting in a limitation of pollen quantity and reduced production of fruits and seeds. Furthermore, plants in small and sparse populations may witness higher within-plant movement of pollinators (Antonovics and Levin, 1980; Klinkhamer and de Jong, 1990; Hermansen et al., 2014), or may be more likely to cross with related individuals (Barrett and Kohn, 1991; Glémin et al. 2008; SuarezGonzalez and Good, 2014). In self-incompatible plants, within-plant pollinator movements or crossing with related individuals decrease compatible pollen receipt,

\section{穴}


which can reduce reproductive success (Waites and Ågren, 2004). In self-compatible plants, within-plant pollinator movements or crossing with related individuals lead to greater self-fertilization rates (van Treuren et al., 1993; Karron, 1995) or biparental inbreeding (Jones and Comita, 2008), potentially decreasing offspring quantity or quality. Finally, if the population size and density are positively correlated with habitat quality, plant size and reproductive success may increase in response to increasing population size and density (Leimu et al., 2006). Literature reviews on this topic have indicated that a positive correlation between reproductive success and population size or density is a common phenomenon in rare and endangered species (Ghazoul, 2005; Leimu et al., 2006).

Notwithstanding the above points, pollination and reproductive success may not always be curtailed in small and sparse populations. For example, plants in such populations may experience lower competition for pollinator visits than those in large and dense populations (Steven et al., 2003). If fruit or seed set is pollinator-limited and pollinators visit a smaller proportion of flowers per plant in large and dense rather than small and sparse populations, then reproductive success may decline in large and dense populations, particularly in self-incompatible species (Johnson et al., 2012; Stein et al., 2013; Ward et al., 2013). Plants facing chronic pollinator scarcity and pollen limitation may evolve selfcompatibility for reproductive assurance (Baker, 1967), and are expected to be less subject to reduced pollinator visitation and the effects of fragmentation (Aguilar et al., 2006). Furthermore, reproductive success in plants in sparse populations may benefit from lower competition for resources, such as light, soil nutrients and water. As a result, plant size and reproductive success may decrease with plant density (Harper, 1977; Antonovics and Levin, 1980; Weiner, 1982; Mustajärvi et al., 2001).

When assessing the effects of habitat fragmentation on reproductive success, some researchers have focused on the population level: population size (number of individuals) and/ or mean population density (Ågren, 1996; Morgan, 1999; Hermansen et al., 2014). On the other hand, others have focused on the individual level: nearest neighbor distance (NND) (Allison, 1990; Metcalfe and Kunin, 2006; CaraballoOrtiz et al., 2011; Lawes et al., 2013) or local neighbor size (LNS) (Roll et al., 1997; Mitchell and Ankeny, 2001; Jakobsson et al., 2009; Weber and Kolb 2013). Although the perspective from either level can provide valuable insight into the effects of habitat fragmentation, few studies have investigated the effects of habitat fragmentation on reproductive success at both levels within a single species (Wagenius, 2006; Gunton and Kunin, 2007; Spigler and Chang, 2008).

In this study, we explored the effects of habitat fragmentation on reproductive success in the endangered annual Circaeaster agristis, at both population (population size and density) and individual (NND and LNS) levels, in 2010 and 2011. The data obtained here may assist in understanding the effects of fragmentation on plant reproductive success, and provide useful guidelines for the management and conservation of $C$. agristis.

\section{Methods}

\section{Study species}

Circaeaster agristis Maxim. is the only species of the genus Circaeaster, which is a member of Circaeasteraceae together with another monotypic genus, Kingdonia (Tian et al., 2007). Circaeaster agristis is an annual alpine herb, narrowly distributed in southwestern and northwestern China. This species primarily grows in humus-rich forest soils. Its population is declining and its distribution range is shrinking because of deforestation and habitat fragmentation, and has consequently been listed as a rare and endangered species in the Chinese red list (Fu and Jin, 1992). It reproduces exclusively by seeds. Individual plants of C. agristis produce a single stem which is, on average, $7.2 \pm$ $2.2 \mathrm{~cm}$ (mean $\pm \mathrm{SD}$, range $=4.3-12.9 \mathrm{~cm}, n=60$, unpublished data) tall. The flowers are green, hermaphroditic and about $1 \mathrm{~mm}$ long, have two or three tepals, one or two stamens, and one carpel (Hu et al., 1990). Flowering occurs from late May to early June, and fruits mature in August. The fruit is an elliptic achene, and is $6-12 \mathrm{~mm}$ long when mature. Each achene contains one seed. The upper surface of the fruit exhibits hooked trichomes.

\section{Study site}

Our experiment was conducted in the Wanglang Nature Reserve $\left(32^{\circ} 49^{\prime}-33^{\circ} 02^{\prime} \mathrm{N}, 103^{\circ} 55^{\prime}-104^{\circ} 10^{\prime}\right.$ E, $2300-$ $4980 \mathrm{~m}$ above sea level), southwestern China. The vertical distribution of vegetation types in this region includes mixed forests of conifers and broadleaf trees, and broadleaf deciduous forest (2300-2600 m), fir forest (dominated by Abies faxoniana) and spruce-cypress forest (dominated by Picea purpurea and Sabina saltuaria, 2600-3500 m), subalpine shrubs and meadow (3500-4400 m), and sparse alpine vegetation (4400-4900 m).

\section{Population size and density}

In 2010, we identified 34 C. agristis populations (Table 1). Three populations disappeared in 2011, but another four populations were identified in this year (Table 1). The populations selected for analysis were present at between 2503 and $2645 \mathrm{~m}$ altitude. All selected populations were present in a forest and were separated from one another by at least $30 \mathrm{~m}$. Natural $C$. agristis populations are patchy and discrete, and are easy to delimit. In early to midAugust of each year, we measured the perimeter of each population, calculating its area, and then counted the number of individual plants (population size). We then estimated the mean density of each population by dividing its population size by its area. The log-transformed mean 
Table 1 Summary data for study populations including location, population size and population density

\begin{tabular}{|c|c|c|c|c|c|c|}
\hline \multirow[t]{2}{*}{ Population } & \multicolumn{2}{|l|}{ Location } & \multicolumn{2}{|c|}{ Population size } & \multicolumn{2}{|c|}{ Population density (number of plants $/ \mathrm{m}^{2}$ ) } \\
\hline & Latitude & longitude & 2010 & 2011 & 2010 & 2011 \\
\hline 1 & $32^{\circ} 58^{\prime} 32^{\prime \prime}$ & $104^{\circ} 04^{\prime} 33^{\prime \prime}$ & 312 & 93 & 118 & 38 \\
\hline 2 & $32^{\circ} 58^{\prime} 35^{\prime \prime}$ & $104^{\circ} 04^{\prime} 35^{\prime \prime}$ & 15434 & 32647 & 230 & 211 \\
\hline 3 & $32^{\circ} 58^{\prime} 05^{\prime \prime}$ & $104^{\circ} 04^{\prime} 38^{\prime \prime}$ & 25 & 7 & 71 & 28 \\
\hline 4 & $32^{\circ} 58^{\prime} 44^{\prime \prime}$ & $104^{\circ} 04^{\prime} 43^{\prime \prime}$ & 18433 & 29277 & 146 & 122 \\
\hline 5 & $32^{\circ} 58^{\prime} 42^{\prime \prime}$ & $104^{\circ} 04^{\prime} 50^{\prime \prime}$ & 8062 & 13961 & 129 & 122 \\
\hline 6 & $32^{\circ} 58^{\prime} 42^{\prime \prime}$ & $104^{\circ} 04^{\prime} 55^{\prime \prime}$ & 715 & 253 & 63 & 21 \\
\hline 7 & $32^{\circ} 58^{\prime} 42^{\prime \prime}$ & $104^{\circ} 04^{\prime} 59^{\prime \prime}$ & 138 & - & 139 & - \\
\hline 8 & $32^{\circ} 58^{\prime} 39^{\prime \prime}$ & $104^{\circ} 05^{\prime} 13^{\prime \prime}$ & 1138 & 7761 & 27 & 117 \\
\hline 9 & $32^{\circ} 58^{\prime} 14^{\prime \prime}$ & $104^{\circ} 05^{\prime} 18^{\prime \prime}$ & 257 & 31 & 612 & 20 \\
\hline 10 & $32^{\circ} 58^{\prime} 34^{\prime \prime}$ & $104^{\circ} 05^{\prime} 19^{\prime \prime}$ & 5166 & 1905 & 118 & 43 \\
\hline 11 & $32^{\circ} 58^{\prime} 28^{\prime \prime}$ & $104^{\circ} 05^{\prime} 21^{\prime \prime}$ & 2137 & 557 & 161 & 40 \\
\hline 12 & $32^{\circ} 58^{\prime} 25^{\prime \prime}$ & $104^{\circ} 05^{\prime} 24^{\prime \prime}$ & 43495 & 22049 & 185 & 87 \\
\hline 13 & $32^{\circ} 58^{\prime} 23^{\prime \prime}$ & $104^{\circ} 05^{\prime} 26^{\prime \prime}$ & 10224 & 7522 & 238 & 139 \\
\hline 14 & $32^{\circ} 58^{\prime} 24^{\prime \prime}$ & $104^{\circ} 05^{\prime} 28^{\prime \prime}$ & 231 & 975 & 27 & 103 \\
\hline 15 & $32^{\circ} 58^{\prime} 26^{\prime \prime}$ & $104^{\circ} 05^{\prime} 30^{\prime \prime}$ & 7231 & 1879 & 272 & 77 \\
\hline 16 & $32^{\circ} 58^{\prime} 11^{\prime \prime}$ & $104^{\circ} 05^{\prime} 37^{\prime \prime}$ & 137 & 302 & 117 & 122 \\
\hline 17 & $32^{\circ} 58^{\prime} 14^{\prime \prime}$ & $104^{\circ} 05^{\prime} 43^{\prime \prime}$ & 156 & 134 & 158 & 61 \\
\hline 18 & $32^{\circ} 58^{\prime} 14^{\prime \prime}$ & $104^{\circ} 05^{\prime} 48^{\prime \prime}$ & 450 & 379 & 58 & 175 \\
\hline 19 & $32^{\circ} 58^{\prime} 15^{\prime \prime}$ & $104^{\circ} 05^{\prime} 54^{\prime \prime}$ & 17 & - & 57 & - \\
\hline 20 & $32^{\circ} 58^{\prime} 16^{\prime \prime}$ & $104^{\circ} 05^{\prime} 59^{\prime \prime}$ & 1315 & 7942 & 33 & 83 \\
\hline 21 & $32^{\circ} 58^{\prime} 40^{\prime \prime}$ & $104^{\circ} 05^{\prime} 08^{\prime \prime}$ & 53 & 428 & 7 & 229 \\
\hline 22 & $32^{\circ} 58^{\prime} 16^{\prime \prime}$ & $104^{\circ} 06^{\prime} 09^{\prime \prime}$ & 3860 & 247 & 283 & 11 \\
\hline 23 & $32^{\circ} 58^{\prime} 16^{\prime \prime}$ & $104^{\circ} 06^{\prime} 12^{\prime \prime}$ & 37519 & 96071 & 309 & 469 \\
\hline 24 & $32^{\circ} 58^{\prime} 09^{\prime \prime}$ & $104^{\circ} 06^{\prime} 13^{\prime \prime}$ & 3774 & 3340 & 165 & 178 \\
\hline 25 & $32^{\circ} 58^{\prime} 12^{\prime \prime}$ & $104^{\circ} 06^{\prime} 16^{\prime \prime}$ & 8138 & 8961 & 134 & 36 \\
\hline 26 & $32^{\circ} 58^{\prime} 07^{\prime \prime}$ & $104^{\circ} 06^{\prime} 17^{\prime \prime}$ & 301 & - & 1158 & - \\
\hline 27 & $32^{\circ} 58^{\prime} 14^{\prime \prime}$ & $104^{\circ} 06^{\prime} 17^{\prime \prime}$ & 4912 & 4417 & 120 & 115 \\
\hline 28 & $32^{\circ} 58^{\prime} 10^{\prime \prime}$ & $104^{\circ} 06^{\prime} 20^{\prime \prime}$ & 85897 & 91925 & 134 & 142 \\
\hline 29 & $32^{\circ} 58^{\prime} 09^{\prime \prime}$ & $104^{\circ} 06^{\prime} 24^{\prime \prime}$ & 1537 & 147 & 422 & 21 \\
\hline 30 & $32^{\circ} 58^{\prime} 09^{\prime \prime}$ & $104^{\circ} 06^{\prime} 29^{\prime \prime}$ & 13657 & 19962 & 184 & 89 \\
\hline 31 & $32^{\circ} 58^{\prime} 02^{\prime \prime}$ & $104^{\circ} 06^{\prime} 46^{\prime \prime}$ & 84500 & 40357 & 285 & 133 \\
\hline 32 & $32^{\circ} 57^{\prime} 59^{\prime \prime}$ & $104^{\circ} 06^{\prime} 56^{\prime \prime}$ & 18084 & 46203 & 239 & 275 \\
\hline 33 & $32^{\circ} 58^{\prime} 00^{\prime \prime}$ & $104^{\circ} 07^{\prime} 02^{\prime \prime}$ & 247 & 554 & 30 & 71 \\
\hline 34 & $32^{\circ} 57^{\prime} 58^{\prime \prime}$ & $104^{\circ} 07^{\prime} 24^{\prime \prime}$ & 426 & 1069 & 12 & 34 \\
\hline 35 & $32^{\circ} 58^{\prime} 11^{\prime \prime}$ & $104^{\circ} 03^{\prime} 18^{\prime \prime}$ & - & 41389 & - & 88 \\
\hline 36 & $32^{\circ} 58^{\prime} 46^{\prime \prime}$ & $104^{\circ} 03^{\prime} 44^{\prime \prime}$ & - & 91669 & - & 109 \\
\hline 37 & $32^{\circ} 58^{\prime} 45^{\prime \prime}$ & $104^{\circ} 03^{\prime} 57^{\prime \prime}$ & - & 17157 & - & 70 \\
\hline 38 & $32^{\circ} 58^{\prime} 29^{\prime \prime}$ & $104^{\circ} 04^{\prime} 20^{\prime \prime}$ & - & 70989 & - & 64 \\
\hline
\end{tabular}

- the population disappeared in 2011 or not found in 2010

population density was significantly correlated to the logtransformed population size in $2010\left(r_{\mathrm{p}}=0.371, P=0.031\right.$, $n=34)$ and $2011\left(r_{\mathrm{p}}=0.614, P<0.001, n=35\right)$.
Sampling on a population basis

From early to mid-August 2010 and 2011 in each population, 30 individuals were randomly marked, except in 
populations with less than 30 individuals, in which case all of them were marked. The number of leaves, flowers (flower scars) and mature fruits were counted on each of the marked individuals.

\section{Sampling on an individual basis}

In August 2011, we randomly marked 35 focal individuals in each of populations 2 (intermediate population density) and 37 (low population density), with the focal plants separated from each other by more than $1 \mathrm{~m}$. For each focal plant, the number of leaves, flowers (flower scars) and mature fruits were counted. The effect of NND was quantified by measuring the distance from each focal plant to the nearest conspecifics. The effect of LNS was quantified by counting the number of conspecifics within radii of $0.1 \mathrm{~m}, 0.2 \mathrm{~m}$, and $0.3 \mathrm{~m}$ around each focal plant. We included areas with multiple radii because the effects of LNS can be scale-dependent (Roll et al., 1997).

\section{Statistical analyses \\ Effects of population size and density on reproduction}

To understand the effects of population size and mean population density, we first calculated the population means of leaf number per plant (plant size), flower number per plant, fruit number per plant, and fruit set (fruits/flowers) per plant, in both 2010 and 2011. We first used linear regression analysis to evaluate the effects of population size and mean population density on mean population fruit number or fruit set for each year separately. Because the population means of plant size were highly correlated with mean population flower number (2010: $r_{\mathrm{p}}=0.865, P<0.001, n=34 ; 2011: r_{\mathrm{p}}=0.861, P<$ 0.001, $n=35)$, fruit number (2010: $r_{\mathrm{p}}=0.782, P<0.001$, $\left.n=34 ; 2011: r_{\mathrm{p}}=0.709, P<0.001, n=35\right)$ and fruit set in $2010\left(r_{\mathrm{p}}=0.583, P<0.001, n=34\right)$, we used a multiple regression analysis to analyze whether population size and mean population density had an influence on mean population fruit number in 2010 and 2011 or on fruit set in 2010, when accounting for mean population plant size. All variables except mean population fruit set were natural-log-transformed to stabilize variances. For all analyses, we examined the residuals for departures from normality (Shapiro-Wilk test).

\section{Effects of NND and LNS on reproduction}

We first used analyses of covariance to analyze fruit number and fruit set of selected individuals as a function of population (random factor) and NND (covariate). Because individual leaf number (plant size) was highly correlated with individual flower number (population 2: $r_{\mathrm{p}}=$ 0.750, $P<0.001, n=35$; population 37: $r_{\mathrm{p}}=0.829, P<$ $0.001, n=35$ ), individual fruit number (population 2: $r_{\mathrm{p}}=$ $0.818, P<0.001, n=35$; population 37: $r_{\mathrm{p}}=0.795, P<$
0.001, $n=35$ ) and individual fruit set (population 2: $r_{\mathrm{p}}=$ $0.531, P=0.001, n=35$; population $37: r_{\mathrm{p}}=0.570, P<$ $0.001, n=35$ ), we then included individual plant size as a covariate in each of the analyses to evaluate whether NND had effects on fruit number or fruit set when differences in individual plant size were accounted for. All variables except fruit set were natural-log-transformed to stabilize variances. For each analysis, initial models included all possible two-way or three-way interactions involving covariates. Non-significant interactions were dropped from the model using backwards elimination. For all analyses, we examined residuals for departures from normality.

Similarly, we used analyses of covariance to analyze fruit number and fruit set as a function of population (random factor) and $0.1 \mathrm{~m} \mathrm{LNS} \mathrm{(covariate),} 0.2 \mathrm{~m} \mathrm{LNS}$ (covariate) and $0.3 \mathrm{~m}$ LNS (covariate). We considered $0.2 \mathrm{~m} \mathrm{LNS}$ and $0.3 \mathrm{~m} \mathrm{LNS}$ as the number of additional individuals beyond $0.1 \mathrm{~m}$ LNS within $0.2 \mathrm{~m}$, and the number of additional individuals beyond $0.2 \mathrm{~m}$ LNS within $0.3-\mathrm{m}$, respectively. Multicollinearity was assessed by inspection of variance inflation factors, which was always $\leq 2.1$, indicating that the level of collinearity was not problematic (Quinn and Keough, 2002). We then included individual plant size as a covariate in each of the analyses to assess whether LNS had effects on fruit number or fruit set when differences in individual plant size were accounted for. Subsequent manipulations of the statistical model were conducted as described previously for NND. All analyses were conducted using SPSS 17.0.

\section{Results}

Effects of population size and density on reproduction

Population means for leaf number per plant varied from 6.5 to 13.0 in 2010 and 7.1 to 11.7 in 2011; population means for flower number per plant varied from 6.5 to 22.2 in 2010 and 9.4 to 32.8 in 2011; population means for fruit number per plant varied from 1.7 to 13.1 in 2010 and 3.0 to 11.9 in 2011. Finally, population means for fruit set per plant varied from 0.14 to 0.59 in 2010 and 0.19 to 0.57 in 2011. All measured traits differed significantly among populations within the same year $(P<0.001$; all variables except fruit set were log-transformed). All correlations were conducted using these log-transformed variables, where applicable.

Mean population fruit number was not correlated to population size in either $2010\left(F_{1,32}=0.036, P=0.850\right)$ or $2011\left(F_{1,33}=1.697, P=0.202\right)$ (Fig. 1a). When mean population plant size was included in the regression analysis of each year, mean population fruit number was not related to population size in either $2010\left(t_{31}=-0.626, P=\right.$ $0.536)$ or $2011\left(t_{32}=0.066, P=0.948\right)$. Meanwhile, mean population fruit number was negatively correlated to mean population density in $2010\left(b \pm s_{\mathrm{b}}=-0.192 \pm 0.075\right.$, $\left.R^{2}=0.169, \quad F_{1,32}=6.500, \quad P=0.016\right), \quad$ and was not 

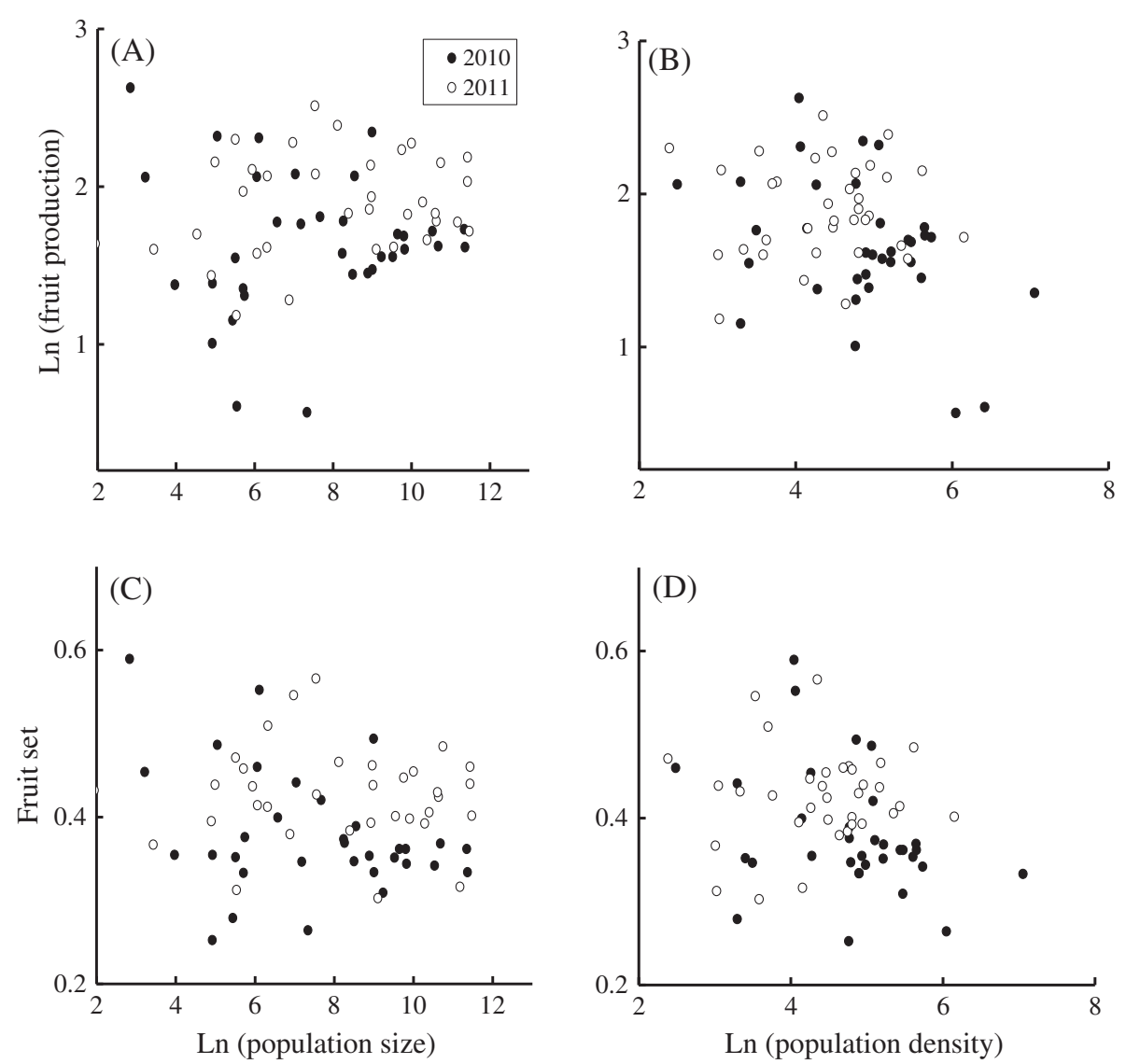

Fig. 1 Effects of population size and density on reproduction in C. agristis. Relationships between population size and (a) mean population fruit production, (c) mean population fruit set, and between mean population density and (b) mean population fruit production and (d) mean population fruit set. Effects of plant size were not accounted for

significantly correlated to mean population density in $2011\left(F_{1,33}=0.076, P=0.785\right)$ (Fig. 1b). When mean population plant size was included in the regression analysis for each year, mean population fruit production was not correlated to mean population density in $2010\left(t_{31}=-0.785\right.$, $P=0.439)$ or $2011\left(t_{32}=0.321, P=0.750\right)$. Furthermore, mean population plant size was negatively correlated to mean population density) in $2010\left(b \pm s_{\mathrm{b}}=-0.064 \pm 0.024\right.$, $R^{2}=0.180, F_{1,32}=7.037, P=0.012$ ).

Mean population fruit set was not related to population size in either $2010\left(F_{1,32}=1.483, P=0.232\right)$ or 2011 $\left(F_{1,33}=0.355, P=0.555\right)$ (Fig. 1c). When mean population plant size was included in the regression analysis for 2010, mean population fruit set was not correlated to population size $\left(t_{31}=-1.700, P=0.099\right)$. Mean population fruit set was negatively correlated to mean population density in $2010\left(b \pm s_{\mathrm{b}}=-0.038 \pm 0.014, R^{2}=0.186\right.$, $\left.F_{1,32}=7.305, P=0.011\right)$, and not correlated to mean population density in $2011\left(F_{1,33}=0.701, P=0.408\right)$ (Fig. 1d). When mean population plant size was included in the regression analysis for 2010, the correlation between mean population fruit set and mean population density became non-significant $\left(t_{31}=-1.436, P=0.161\right)$.

\section{Effects of NND}

Individual plants of populations 2 and 37 respectively produced an average of 10.3 ( $\mathrm{SD}=2.6$, range $=7-18$ ) and $10.6(\mathrm{SD}=2.5$, range $=7-17)$ leaves, and $10.5(\mathrm{SD}=5.6$, range $=2-29)$ and $11.8(\mathrm{SD}=7.9$, range $=3-29)$ fruits. Mean fruit set of individual plants was $0.45(\mathrm{SD}=0.13$, range $=0.25-0.70)$ and $0.47(\mathrm{SD}=0.12$, range $=0.23-$ 0.71 ) in populations 2 and 37 respectively. All of these measured traits did not differ significantly between populations ( $P>0.5$ for all comparisons). Mean NND was $0.020 \mathrm{~m} \quad(\mathrm{SD}=0.019$, range $=0.001-0.081 \mathrm{~m})$ and $0.044 \mathrm{~m}(\mathrm{SD}=0.056$, range $=0.001-0.230 \mathrm{~m})$ in populations 2 and 37 respectively, and differed significantly between populations $\left(F_{1,68}=4.001, P=0.049\right)$.

Individual fruit number did not vary with NND irrespective of whether or not individual plant size was included in the analysis of covariance (Table 2A-B, Fig. 2a). Individual fruit set was positively correlated with NND $\left(b \pm s_{\mathrm{b}}=0.029\right.$ 
Table 2 Individual fruit production and fruit set as a function of population, NND and plant size

\begin{tabular}{llll}
\hline & Effect & Fruit production & Fruit set \\
\hline A & Population & $F_{1,67}=0.006$ & $F_{1,67}=0.020$ \\
& NND & $F_{1,67}=0.512$ & $F_{1,67}=4.807^{*}$ \\
& Model $R^{2}$ & n.s. & 0.069 \\
B & Population & $F_{1,66}=0.500$ & $F_{1,66}=0.063$ \\
& NND & $F_{1,66}=3.015$ & $F_{1,66}=9.664^{* *}$ \\
& Plant size & $F_{1,66}=125.026^{* * *}$ & $F_{1,66}=33.551^{* * *}$ \\
& Model $R^{2}$ & 0.657 & 0.383 \\
\hline
\end{tabular}

n.s. $=$ not significant, ${ }^{*} P<0.01,{ }^{* *} P<0.01,{ }^{* * *} P<0.001$

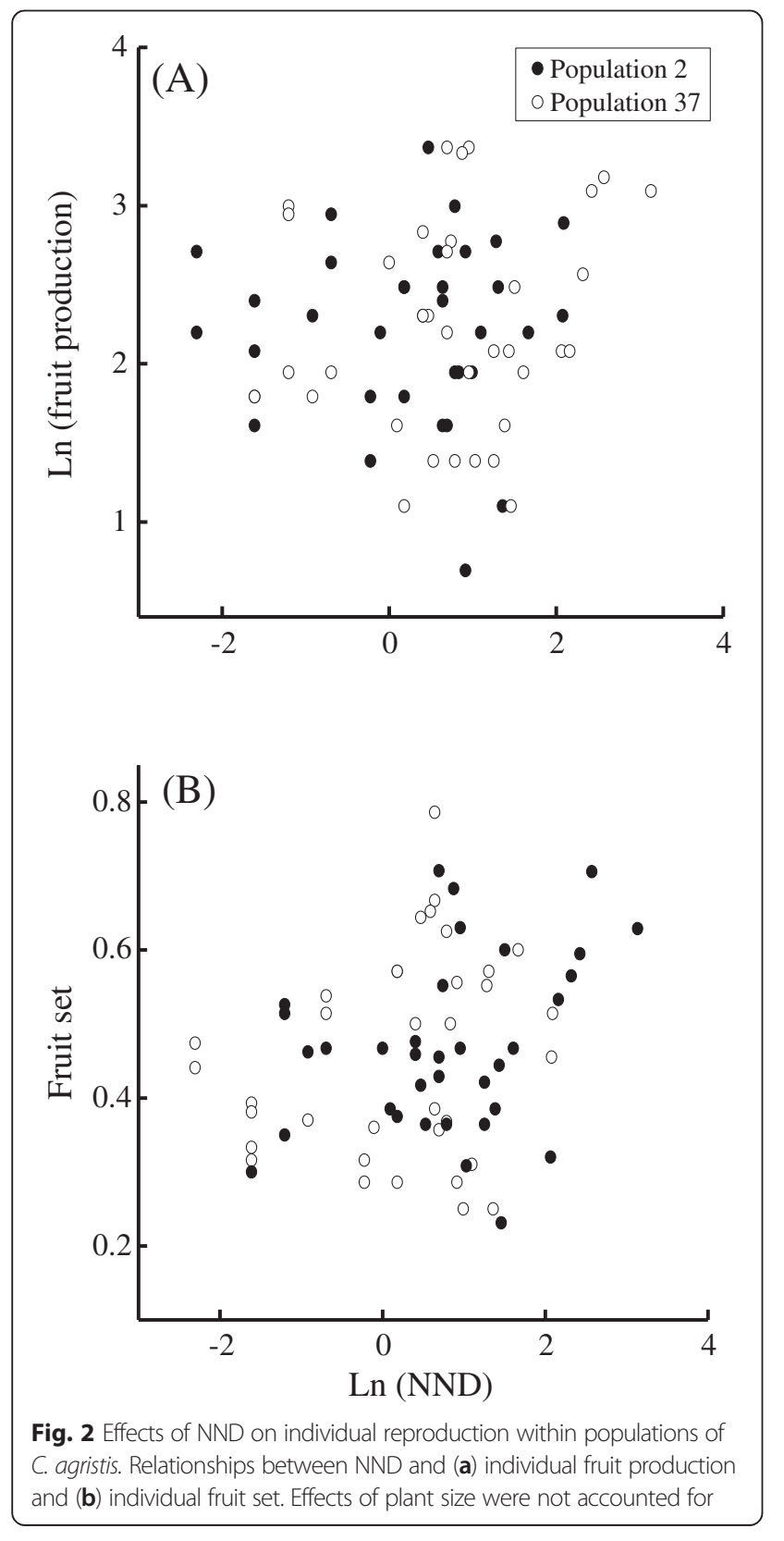

\pm 0.013 , Table $2 \mathrm{~A}$, Fig. $2 \mathrm{~b}$ ). When individual plant size was included in the analysis of covariance, a positive effect of $\mathrm{NND}$ on individual fruit set remained $\left(b \pm s_{\mathrm{b}}=0.032 \pm\right.$ 0.011 , Table 2B). As expected, individual plant size affected individual fruit number and individual fruit set (Table 2B). Furthermore, individual plant size was not significantly correlated to $\mathrm{NND}\left(F_{1,67}=0.150, P=0.699\right)$.

\section{Effects of LNS}

In populations 2 and 37, the mean $0.1 \mathrm{~m}$ LNS was 15.8 $(\mathrm{SD}=10.6$, range $=2-40)$ and $9.5(\mathrm{SD}=10.0$, range $=1-56)$, respectively. Similarly, the mean $0.2 \mathrm{~m}$ LNS was $24.3(\mathrm{SD}=$ 18.8 , range $=3-72)$ and $12.3(\mathrm{SD}=11.3$, range $=1-45)$, respectively, while the mean $0.3 \mathrm{~m}$ LNS was $28.3(\mathrm{SD}=$ 28.0, range $=4-137)$ and $18.6(\mathrm{SD}=24.5$, range $=1-131)$, respectively. All pairwise contrasts between populations were significant $(P<0.05)$.

Individual fruit production was negatively correlated to $0.1 \mathrm{~m}$ LNS $\left(b \pm s_{\mathrm{b}}=-0.269 \pm 0.075\right.$, Table 3A, Fig. 3a), and was not correlated to $0.2 \mathrm{~m}$ LNS or $0.3 \mathrm{~m}$ LNS (Table 3A). When individual plant size was included in the analysis of covariance, individual fruit production was again negatively correlated to $0.1 \mathrm{~m} \mathrm{LNS}\left(b \pm s_{\mathrm{b}}=-0.127 \pm 0.056\right.$, Table 3B), and was not correlated to $0.2 \mathrm{~m}$ LNS or $0.3 \mathrm{~m}$ LNS (Table 3B). Furthermore, individual plant size was negatively correlated to $0.1 \mathrm{~m}$ LNS $\left(b \pm s_{\mathrm{b}}=-0.096 \pm 0.032\right.$, $\left.F_{1,65}=9.133, P=0.004\right)$, and was not correlated to $0.2 \mathrm{~m}$ LNS $\left(F_{1,65}=3.775, P=0.056\right)$ or $0.3-\mathrm{m}$ LNS $\left(F_{1,65}=0.033\right.$, $P=0.856)$.

Individual fruit set was negatively correlated to $0.1 \mathrm{~m}$ LNS ( $b \pm s_{\mathrm{b}}=-0.068 \pm 0.015$, Table 3A, Fig. $\left.3 \mathrm{~b}\right)$, and was not correlated to $0.2 \mathrm{~m}$ LNS or $0.3 \mathrm{~m} \mathrm{LNS} \mathrm{(Table} \mathrm{3A).}$ When individual plant size was included in the analysis of covariance, individual fruit set was again negatively

Table 3 Individual fruit production and fruit set as a function of population, LNS and plant size

\begin{tabular}{llll}
\hline & Effect & Fruit production & Fruit set \\
\hline A & Population & $F_{1,65}=0.555$ & $F_{1,65}=1.391$ \\
& $0.1 \mathrm{~m}$ LNS & $F_{1,65}=15.213^{* * *}$ & $F_{1,65}=16.637^{* * *}$ \\
$0.2 \mathrm{~m}$ LNS & $F_{1,65}=2.807$ & $F_{1,65}=0.162$ \\
& $0.3 \mathrm{~m} \mathrm{LNS}$ & $F_{1,65}=1.019$ & $F_{1,65}=0.691$ \\
& Model $R^{2}$ & 0.196 & 0.244 \\
B & Population & $F_{1,64}=2.227$ & $F_{1,64}=2.289$ \\
& $0.1 \mathrm{~m}$ LNS & $F_{1,64}=5.252^{*}$ & $F_{1,64}=7.445^{* *}$ \\
& $0.2 \mathrm{~m}$ LNS & $F_{1,64}=0.055$ & $F_{1,64}=0.468$ \\
& $0.3 \mathrm{~m}$ LNS & $F_{1,64}=1.924$ & $F_{1,64}=0.731$ \\
& Plant size & $F_{1,64}=102.676^{* * *}$ & $F_{1,64}=23.627^{* * *}$ \\
& Model $R^{2}$ & 0.691 & 0.448 \\
\hline
\end{tabular}




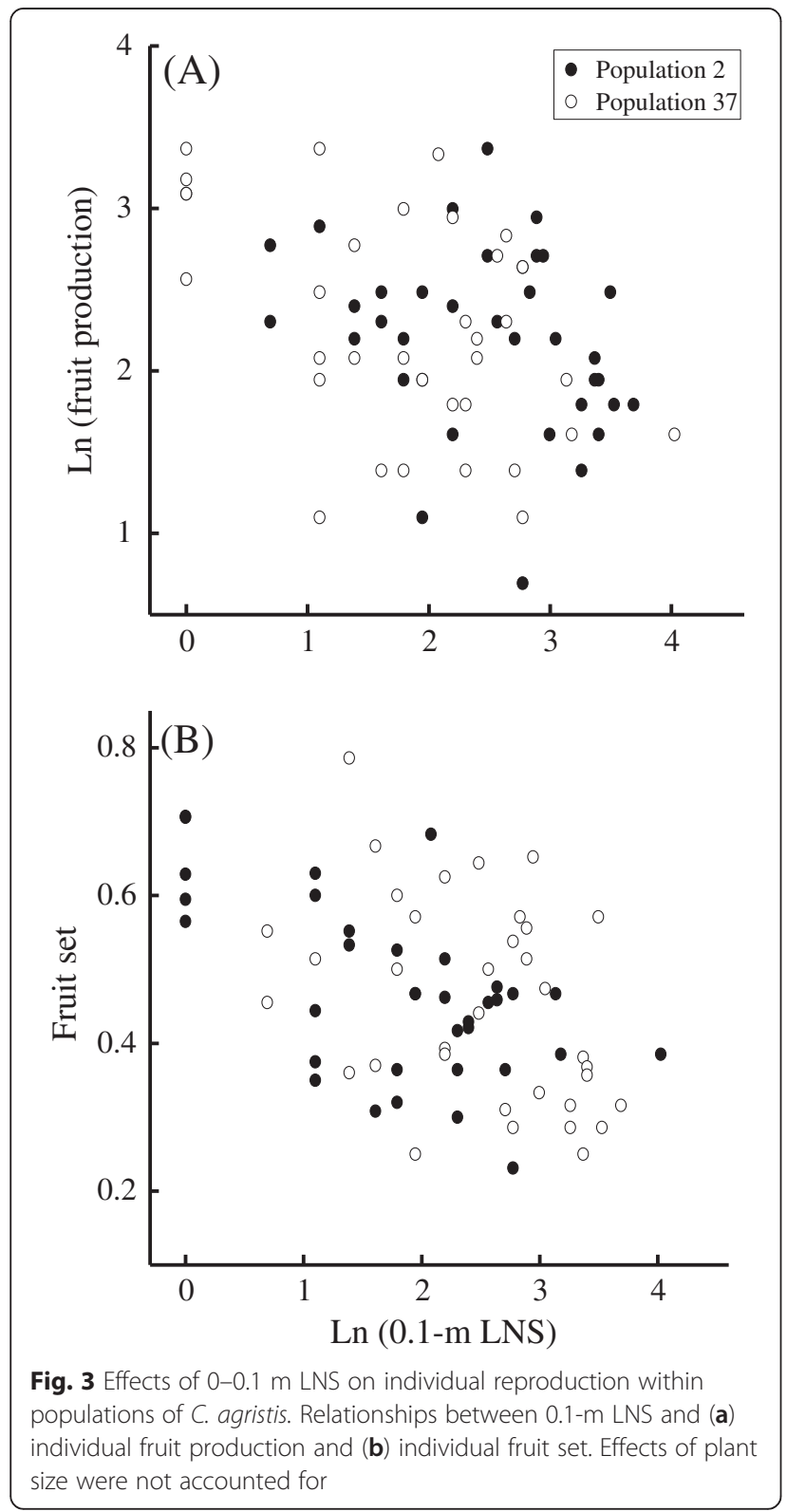

correlated to $0.1 \mathrm{~m}$ LNS $\left(b \pm s_{\mathrm{b}}=-0.042 \pm 0.015\right.$, Table 3B), and was not correlated to $0.2 \mathrm{~m} \mathrm{LNS}$ or $0.3 \mathrm{~m} \mathrm{LNS}$ (Table 3B).

\section{Discussion}

\section{Effects of habitat fragmentation on reproduction at the population level}

The effects of population size on reproduction have been widely studied (Ghazoul, 2005; Aguilar et al., 2006; Leimu et al., 2006). There is a large body of evidence indicating that plants of small populations have lower fruit or seed production than those of large populations because of insufficient pollen quantity and poor pollen quality (e.g. Ågren 1996; Tomimatsu and Ohara, 2002; Brys et al., 2004; Waites and Ågren, 2004; Hermansen et al., 2014). However, we did not detect such a pattern in $C$. agristis in either of the years studied, possibly because pollen quantity and quality are not related to its population size. No relationships between fruit or seed number per plant and population size have been reported in some studies (e.g. Alexandersson and Ågren, 1996; Molano-Flores et al. 1999; Spigler and Chang, 2008), suggesting that positive relationships between population size and either pollination or reproduction maybe not the rule. Alternatively, a lack of population size effects might arise if studies examining the effects of population size require the sampling of a wide range of population sizes. This explanation cannot be applied to our results, given that our study included, in both years of study, both populations with only a few individuals and populations with about 100, 000 individuals (Table 1).

In contrast to the vast majority of studies reporting a positive correlation between fruit or seed number per plant and population density (Ghazoul, 2005; Wagenius, 2006; Brys et al., 2008; Feldman, 2008), the effects of population density on mean population fruit number and fruit set in C. agristis varied between years, from negative in 2010 to neutral in 2011. As indicated in Table 1, Fig. 1b and Fig. 1d, some populations (9, 26 and 29) surveyed in 2010 were very dense, and it is possible that a negative correlation between population density and mean population fruit number or fruit set for $C$. agristis may be detectable only when dense populations are surveyed. Our findings support the idea that a 1-year study may not provide a realistic view of the effects of fragmentation on plant reproduction (Hobbs and Yates, 2003). However, when population plant size was accounted for, no relationship between population density and mean population fruit production or fruit set was evident in either year. These results suggest that the effects of population density on mean population fruit production and fruit set in 2010 were exerted indirectly via a negative effect on population plant size, and that pollination was independent of population density. A negative relationship between population density and mean population plant size might arise if competition for resources increases with density, reducing resource availability for plants in populations of high density (Harper, 1977).

\section{Effects of habitat fragmentation on reproduction at the individual level within populations}

Many studies have shown that the reproductive success of individual plants may decrease in response to increasing NND or decreasing LNS due to pollen limitation (Allison, 1990; Roll et al. 1997; Jakobsson et al., 2009; Caraballo-Ortiz et al., 2011). Contrary to these studies, individual fruit set of $C$. agristis in our study increased in response to increasing NND and decreased with 
increasing LNS at the $0.1 \mathrm{~m}$ spatial scale, and these relationships remained even when individual plant size was accounted for. These results are highly suggestive of intra-specific competition for resources: competition for resources decreased with increasing NND and increased with increasing LNS at the $0.1 \mathrm{~m}$ spatial scale during fruit maturation. Individual fruit production in $C$. agristis decreased with increasing LNS at the $0.1 \mathrm{~m}$ spatial scale but did not change in response to NND when individual plant size was accounted for; this indicates that competition for resources between the focal individual and the nearest conspecific individual may have been too weak to affect fruit production in the focal plants. Similarly, individual plant size of $C$. agristis decreased with increasing LNS at the $0.1 \mathrm{~m}$ spatial scale but did not change in response to NND, suggesting that intraspecific competition for resources between neighboring plants during growth was not strong enough to be detected when only the nearest conspecific was considered. These results also suggest that plants of $C$. agristis with fewer neighbors within a $0.1 \mathrm{~m}$ radius would benefit from not only a direct negative effect of LNS on reproductive success, but also from an indirect negative effect of LNS on reproductive success, namely via its effect on plant size. This is because large individuals typically have a higher fruit set than small individuals. However, these effects were not evident at the $0.2 \mathrm{~m}$ and $0.3 \mathrm{~m}$ spatial scales, suggesting that competition for resources in C. agristis occurs on very local scales.

\section{Conclusions}

The results of our study indicate that the reproductive success of $C$. agristis does not respond negatively to habitat fragmentation. Although previous studies on both agricultural and experimental populations have shown that high plant density may reduce fruit or seed production through competition and/or plant size (Harper, 1977; Antonovics and Levin, 1980; Weiner, 1982; Mustajärvi et al., 2001), our study is an instance of negative density-dependent reproduction occurring in a rare and endangered species in the wild. Furthermore, our findings highlight the view that any studies of the effects of fragmentation on reproduction should consider multiple spatial scales (Wagenius, 2006; Gunton and Kunin, 2007; Spigler and Chang, 2008).

Our study has implications for the conservation and management of $C$. agristis. First, our finding that C. agristis populations are distributed patchily on forest floors after fragmentation suggests that the maintenance of $C$. agristis habitat should be a priority. Second, small and sparse populations are as important as large and dense populations from a conservation perspective, because the former will be at least as successful, if not more, at reproduction, compared to large and dense populations. Third, a program aimed at re-establishing populations of this species should consider increasing the spacing between plants (compared to populations in the wild), which may reduce competition for resources and thereby increase fruit production.

\section{Competing interests}

The authors declare that they have no competing interests.

\section{Authors' contributions}

CGX conceived and designed the experiments. ZJC, LJ, YCP performed the experiments. CGX analyzed the data. CGX, ZJC wrote the manuscript. All authors read and approved the final manuscript.

\section{Acknowledgements}

This research was supported by the National Natural Science Foundation of China (Project no. 30870388, 31370436).

Received: 13 December 2014 Accepted: 24 May 2015

Published online: 02 June 2015

\section{References}

Ågren J (1996) Population size, pollinator limitation, and seed set in the self-incompatible herb Lytrhum salicaria. Ecology 77:1779-1790

Aguilar R, Ashworth L, Galetto L, Aizen MA (2006) Plant reproductive susceptibility to habitat fragmentation: review and synthesis through a meta-analysis. Ecol Lett 9:968-980

Alexandersson R, Ågren J (1996) Population size, pollinator visitation and fruit production in the deceptive orchid Calypso bulbosa. Oecologia 107:533-540

Allison TD (1990) Pollen production and plant density affect pollination and seed production in Taxus canadensis. Ecology 71:516-522

Antonovics J, Levin DA (1980) The ecological and genetic consequences of density-dependent regulation in plants. Annu Rev Ecol Syst 11:411-452

Baker HG (1967) Support for Baker's law-as a rule. Evolution 21:853-856

Barrett SCH, Kohn JR (1991) Genetic and evolutionary consequences of small population size in plants: implication for conservation. In: Falk DA, Holsinger KE (eds) Genetics and Conservation of Rare Plants. Oxford University Press, New York

Bosch M, Waser NM (1999) Effects of local density on pollination and reproduction in Delphinium nuttallianum and Aconitum columbianum (Ranuculaceae). Amer J Bot 86:871-879

Brys $R$, Jacquemyn $H$, Endels $P$, Van Rossum F, Hermy M, Triest $L$, de Bruyn $L$, Blust GDE (2004) Reduced reproductive success in small populations of the self-incompatible Primula vulgaris. J Ecol 92:5-14

Brys R, Jacquemyn H, Hermy M (2008) Pollination efficiency and reproductive patterns in relation to local plant density, population size, and floral display in the rewarding Listera ovata (Orchidaceae). Bot J Linn Soc 157:713-721

Caraballo-Ortiz MA, Santiago-Valentín E, Carlo TA (2011) Flower number and distance to neighbours affect the fecundity of Goetzea elegans (Solanaceae). J Trop Ecol 27:521-528

Eriksson O, Ehrlén J (2001) Landscape fragmentation and the viability of plant populations. In: Silvertown J, Antonovics J (eds) Integrating Ecology and Evolution in a Spatial Context. Blackwell Science, Oxford

Feldman TS (2008) The plot thickens: does low density affect visitation and reproductive success in a perennial herb, and are these effects altered in the presence of a co-flowering species? Oecologia 156:807-807

Fu LK, Jin JM (1992) China Plant Red Data Book: Rare and Endangered Plants. Science Press, Beijing

Ghazoul J (2005) Pollen and seed dispersal among dispersed plants. Biol Rev 80:413-443

Glémin S, Petit C, Maurice S, Mignot A (2008) Consequences of low mate availability in the rare self-incompatible species Brassica insularis. Conserv Biol 22:216-221

Gunton RM, Kunin WE (2007) Density effects at multiple scales in an experimental plant population. J Ecol 95:435-445

Harper JL (1977) Population Biology of Plants. Academic, New York

Hermansen TD, Ayre DJ, Minchinton TE (2014) Effects of stand size on pollination in temperate populations of the mangrove Avicennia marina. Plant Ecol 215:1153-1162 
Hobbs RJ, Yates CJ (2003) Impacts of ecosystem fragmentation on plant populations: generalizing the idiosyncratic. Aust J Bot 51:471-488

Hu ZH, Yang J, Jing RQ, Dong ZM (1990) Morphology studies on Circaeaster agrestis II. Morphology and anatomy of flower, fruit and seed. Cathaya 2:77-88

Jakobsson A, Lázaro A, Totland $\varnothing$ (2009) Relationships between the floral neighborhood and individual pollen limitation in two self-incompatible herbs. Oecologia 160:707-719

Johnson SD, Hollens H, Kulhmann M (2012) Competition versus facilitation: conspecific effects on pollinator visitation and seed set in the iris Lapeirousia oreogena. Oikos 121:545-550

Jones FA, Comita LS (2008) Neighbourhood density and genetic relatedness interact to determine fruit set and abortion rates in a continuous tropical tree population. Proc R Soc Lond B 275:2759-2767

Karron JD (1995) The influence of population density on outcrossing rates in Mimulus ringens. Heredity 75:175-180

Klinkhamer PGL, de Jong TJ (1990) Effects of plant size, plant density and sex differential nectar reward on pollinator visitation in the protandrous Echium vulgare (Boraginaceae). Oikos 57:399-405

Kunin WE (1997) Population size and density effects in pollination: pollinator foraging and plant reproductive success in experimental arrays of Brassica kaber. J Ecol 85:225-234

Lawes MJ, Taplin P, Bellairs SM, Franklin DC (2013) A trade-off in stand size effects in the reproductive biology of a declining tropical conifer Callitris intratropica. Plant Ecol 214:169-174

Leimu R, Mutikainen P, Koricheva J, Fischer M (2006) How general are positive relationships between plant population size, fitness and genetic variation? J Ecol 94:942-952

Metcalfe DB, Kunin WE (2006) The effects of plant density upon pollination success, reproductive effort and fruit parasitism in Cistus ladanifer $\mathrm{L}$. (Cistaceae). Plant Ecol 185:41-47

Mitchell RJ, Ankeny DP (2001) Effects of local conspecific density on reproductive success in Penstemon digitalis and Hesperis matronalis. Ohio J Sci 101:22-27

Molano-Flores B, Hendrix SD, Heard SB (1999) The effect of population size on stigma pollen load, fruit set, and seed set in Allium stellatum ker. (Liliaceae). Int J Plant Sci 160:753-757

Morgan JW (1999) Effects of population size on seed production and germinability in an endangered, fragmented grassland plant. Conserv Biol $13: 266-273$

Mustajärvi K, Siikamäki P, Rytkönen S, Lammi A (2001) Consequences of plant population size and density for plant-pollinator interactions and plant performance. J Ecol 89:80-87

Oostermeijer JGB (2003) Threats to rare plant persistence. In: Brigham CA, Schwartz MW (eds) Population Viability in Plants: Conservation, Management, and Modeling of Rare Plants. Springer, Berlin

Quinn GP, Keough MJ (2002) Experimental design and data analysis for biologists. Cambridge University Press, Cambridge

Roll J, Mitchell RJ, Cabin RJ, Marshall DL (1997) Reproductive success increases with local density of conspecifics in a desert mustard (Lesquerella fenleri) Conserv Biol 11:738-746

Saunders DA, Hobbs RJ, Margules CR (1991) Biological consequences of ecosystem fragmentation: a review. Conserv Biol 5:18-32

Spigler RB, Chang SM (2008) Effects of plant abundance on reproductive success in the biennial Sabatia angularis (Gentianaceae): spatial scale matters. J Ecol 96:323-333

Stein K, Templin M, Hensen I, Fischer M, Matthies D, Schleuning M (2013) Negative effects of conspecific floral density on fruit set of two neotropical understory plants. Biotropica 45:325-332

Steven JC, Rooney TP, Boyle OD, Waller DM (2003) Density dependent pollinator visitation and self-incompatibility in upper Great Lakes populations of Trillium grandiflorum. J Torrey Bot Soc 130:23-29

Suarez-Gonzalez A, Good SV (2014) Pollen limitation and reduced reproductive success are associated with local genetic effects in Prunus virginiana, a widely distributed self-incompatible shrub. Ann Bot 113:595-605

Tian XH, Zhao L, Ren Y, Zhang XH (2007) Number of floral organs in Circaeaster agrestis (Circaeasteraceae) and possible homeosis among floral organs. Plant Syst Evol 265:259-265

Tomimatsu H, Ohara M (2002) Effects of forest fragmentation on seed production of the understory herb trillium camschatcense. Conserv Biol 16:1277-1285

Van Treuren R, Bulsma R, Ouborg NJ, Van Delden W (1993) The effects of population size and plant density on outcrossing rates in locally endangered Salvia pratensis. Evolution 47:1094-1104
Wagenius S (2006) Scale dependence of reproductive failure in fragmented Echinacea populations. Ecology 87:931-941

Waites AR, Ågren J (2004) Pollinator visitation, stigmatic pollen loads, and amongpopulation variation in seed set in Lythrum salicaria. J Ecol 92:512-526

Ward M, Johnson SD, Zalucki MP (2013) When bigger is not better: intraspecific competition for pollination increases with population size in invasive milkweeds. Oecologia 171:883-891

Weber A, Kolb A (2013) Local plant density, pollination and trait-fitness relationships in a perennial herb. Plant Biol 15:335-343

Weiner J (1982) A neighborhood model of annual-plant interference. Ecology 63:1237-1241

Wilcove DS, McLellan CH, Dobson AP (1986) Habitat fragmentation in the temperate zone. Conserv Biol 6:237-256

\section{Submit your manuscript to a SpringerOpen ${ }^{\odot}$ journal and benefit from:}

- Convenient online submission

- Rigorous peer review

- Immediate publication on acceptance

- Open access: articles freely available online

- High visibility within the field

- Retaining the copyright to your article

Submit your next manuscript at $>$ springeropen.com 